\title{
Sensitivity of storm waves in Montevideo (Uruguay) to a hypothetical climate change
}

\author{
Eugenio Lorenzo*, Luis Teixeira \\ Instituto de Mecánica de los Fluidos e Ingeniería Ambiental, Facultad de Ingeniería, Universidad de la República, \\ J. Herrera Y Reissig 565, 11300 Montevideo, Uruguay
}

\begin{abstract}
Outputs from the application of a simple storm wave generation model using real wind data for several years in the 1980s are compared with simulations representing conditions of a $10 \%$ higher wind strength and a $1 \mathrm{~m}$ sea-level rise. A numeric wave propagation model (combined refraction-diffraction) is also used to calculate propagation coefficients for waves approaching the Montevideo coast under 2 different scenarios. The first one (baseline scenario) describes the current situation, while the second one reflects a $1 \mathrm{~m}$ rise in sea level. The analysis of propagation coefficients is carried out for all directions of the wind waves approaching the Montevideo shoreline, using the most representative wave period and height in each case. As a general conclusion it is observed that, under such a climate change scenario, storm waves would increase in height, while their angle of incidence would remain unchanged.
\end{abstract}

KEY WORDS: Wave climate - Wave generation - Wave propagation Climate change - Sea-level rise

\section{INTRODUCTION}

Montevideo, capital city of the Republic of Uruguay, is located on the coast of the Río de la Plata, a very large but relatively shallow estuary.

Studies on the waves approaching the city coastline have been carried out at the Instituto de Mecánica de los Fluidos e Ingeniería Ambiental (IMFIA) of the Facultad de Ingeniería, Universidad de la República. Storm wave climate estimates for Montevideo, based on the application of a simple wind wave generation model using hourly wind data from a 15 yr period, are presently available (Teixeira \& Lorenzo 1995).

Montevideo has a population of about 1.5 million (almost $50 \%$ of the country's total population), most of which has settled within a coastal area less than $5 \mathrm{~km}$ wide. Wind waves are the most relevant factor as regards the impacts of the sea on coastal structures. The swell, although more persistent, has considerably lower amplitudes.

This study applies Step 4 of the 'common methodology for vulnerability analyses' (assessment of physical

•E-mail: elorenzo@fing.edu.uy changes and natural system responses) developed by the Intergovernmental Panel on Climate Change Coastal Zone Management Subgroup (IPCC CZMS).

The climate change scenario used is based on the assumption of a $1 \mathrm{~m}$ rise in sea level and a $10 \%$ increase in wind strength, with no change in wind direction. The wind wave pattern for 2 years randomly selected from the 1979 to 1994 period-for which hourly wind records are available-was analyzed under this scenario.

\section{METHODOLOGY}

\subsection{General considerations}

Wave generation and propagation were simulated independently using 2 different models. Storm wave generation was performed under a $1 \mathrm{~m}$ sea-level rise scenario with a $10 \%$ increase in wind strength. Baseline wind conditions consisted of hourly recorded data from 1986 and 1988. The effects of wave propagation are not taken into account in the simulated wave climate. 
A $1 \mathrm{~m}$ sea-level rise was also considered for the study of wave propagation. For this purpose, the refraction and diffraction coefficients were calculated for each wave direction using a wave period and height representative of the respective direction.

The climate change scenario selected is an adaptation of the scenarios used in the 'Impacts of sea-level rise on society' study by Rijkswaterstaat (1991). Furthermore, the $1 \mathrm{~m}$ sea-level rise scenario is the one most commonly adopted in vulnerability studies, as well as in the IPCC's 'A Global Vulnerability Assessment' (IPCC 1994).

\subsection{Wave generation using wind data}

The method known as SPM (CERC 1984), revised by Hurdle \& Stieve (1989), is used in the wave generation model. This is a simple model which estimates the height and period of the generated waves using wind velocity, wind duration and wind reach data.

Given the orientation of the Montevideo coast, only the winds from the E, ESE, SE, SSE, SW, SSW, WSW and $S$ were considered. The recorded wind directions were used under both the baseline and the climate change scenario.

The conditions of the sea at a previous time were taken into account in the estimate of the duration of wind action, in order to evaluate the amount of energy already supplied by winds coming from the same or from an adjacent direction.

\subsection{Wave propagation}

The method used is based on the assumption that the generated storm waves are deep-water waves. The refraction, diffraction and reflection effects of the waves approaching the coastline were analyzed by means of a numerical refraction-diffraction model, derived from the RCPWAVE (Regional Coastal Processes Wave) model (Ebersole et al. 1986). Berkhoff's equation is solved by the main model algorithm by means of a finite difference scheme, taking as variables the wave amplitude and wave phase functions from the complex velocity potential.

The bathymetric data were provided by the 'Servicio de Oceanografía, Hidrografía y Meteorología de la Armada' (SOHMA). Approximately 8000 bathymetric points from the area close to Montevideo were used.

The tide elevation value used for the baseline scenario was $2 \mathrm{~m}$, while a $3 \mathrm{~m}$ tide elevation was assumed for the climate change scenario. The wave height and period most representative of severe storm conditions were selected for each wave direction.

\section{RESULTS}

Storm wave generation results using hourly wind data from the years 1986 and 1988 are presented below. The percentages of the different wave height intervals corresponding to the most significant wave directions under both scenarios are described in Figs. 1 to 6 .

The storm wave roses produced for the baseline and climate change scenarios are displayed on Figs. 7 \& 8 respectively.

The propagation coefficients of the waves most representative of each direction, both for the baseline scenario with a $2 \mathrm{~m}$ tide elevation and for the climate change scenario with $3 \mathrm{~m}$ tide elevation, are shown in Table 1 . The percentage increase in the propagation coefficient between the baseline and the climate change scenarios, as well as the change in the angle of incidence on the coast, is also described.

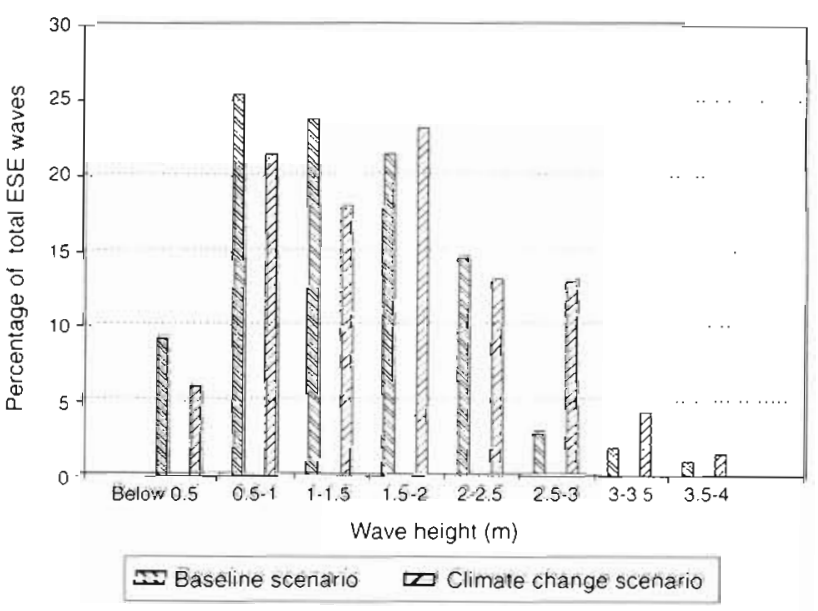

Fig. 1. Distribution of generated wave heights for the ESE direction under baseline and climate change scenarios

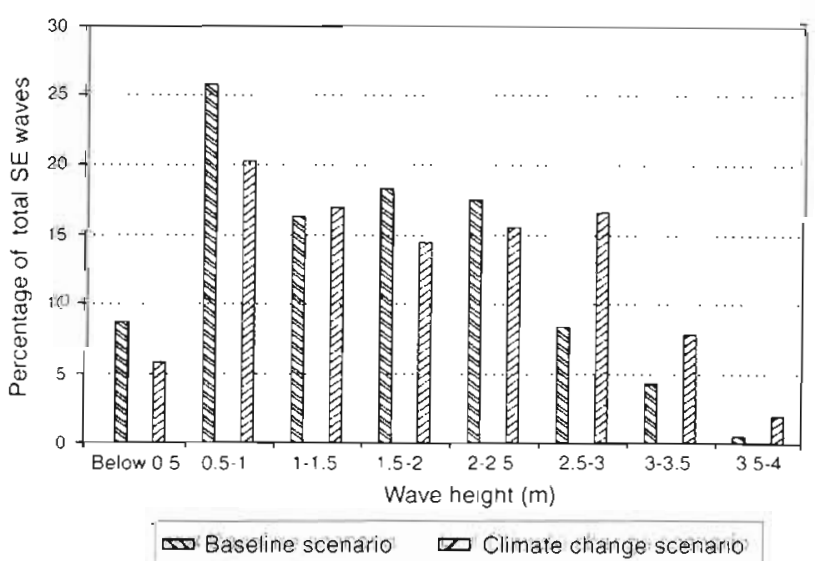

Fig. 2. Distribution of generated wave heights for the SE direction under baseline and climate change scenarios 


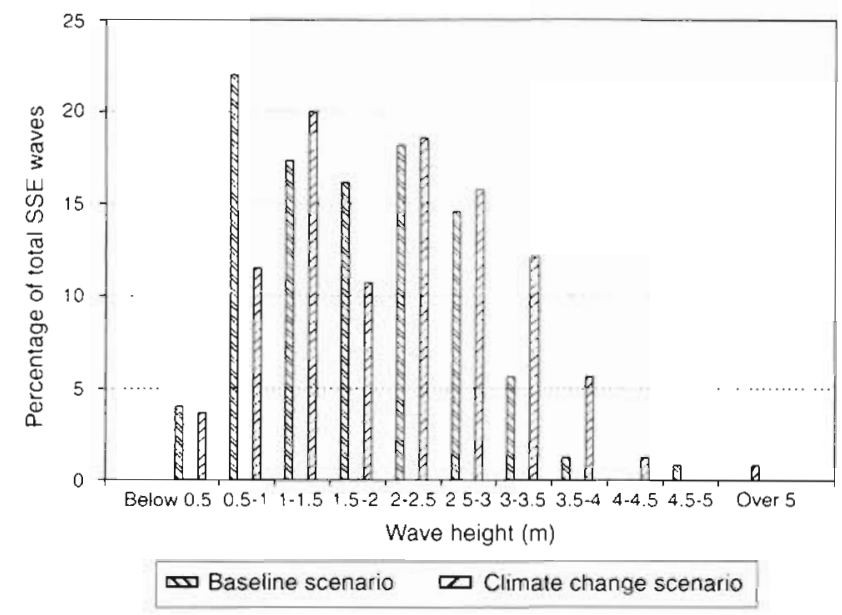

Fig. 3. Distribution of generated wave heights for the SSE direction under baseline and climate change scenarios

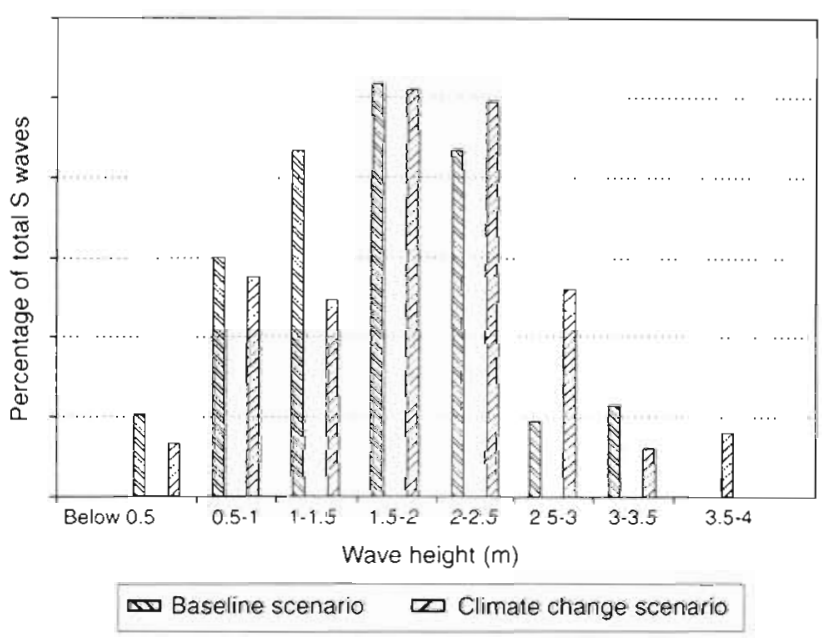

Fig. 4. Distribution of generated wave heights for the $S$ direction under baseline and climate change scenarios

\section{DISCUSSION}

As expected, an increase in the percentage occurrence of the highest generated waves would result from a $10 \%$ increase in wind strength. For example, for the SW direction, $7 \%$ of the generated waves are higher than $1.5 \mathrm{~m}$ under baseline conditions, while this percentage increases to $34 \%$ under the climate change scenario. For the $\mathrm{S}$ direction the percentage of waves higher than $2.5 \mathrm{~m}$ is $12 \%$ under the baseline scenario and $20 \%$ under the climate change scenario, while these values are 12 and $27 \%$ respectively for the SE direction.
According to the data in Table 1, the angles of incidence of the waves on the coast would not be affected by the assumed rise in sea level, since their variation does not exceed $4^{\circ}$ for any direction.

It is not possible, however, to establish a general rule with regard to the propagation coefficient variation. This coefficient either decreases or increases for different wave directions under the sea-level rise scenario as a consequence of the Río de la Plata bathymetric conditions. In any case, the variations in this coefficient do not exceed $10 \%$.

With regard to the potential impact of the climate change conditions on coastal structures, an example can be taken from the design and verification of breakwater revetments. The weight of rocks required for this purpose is estimated based on equations which include

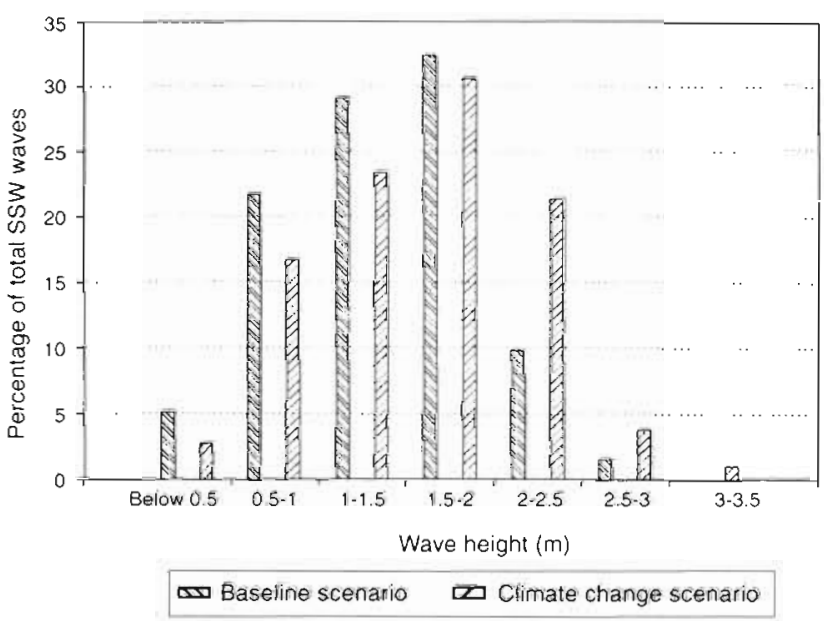

Fig. 5. Distribution of generated wave heights for the SSW direction under baseline and climate change scenarios

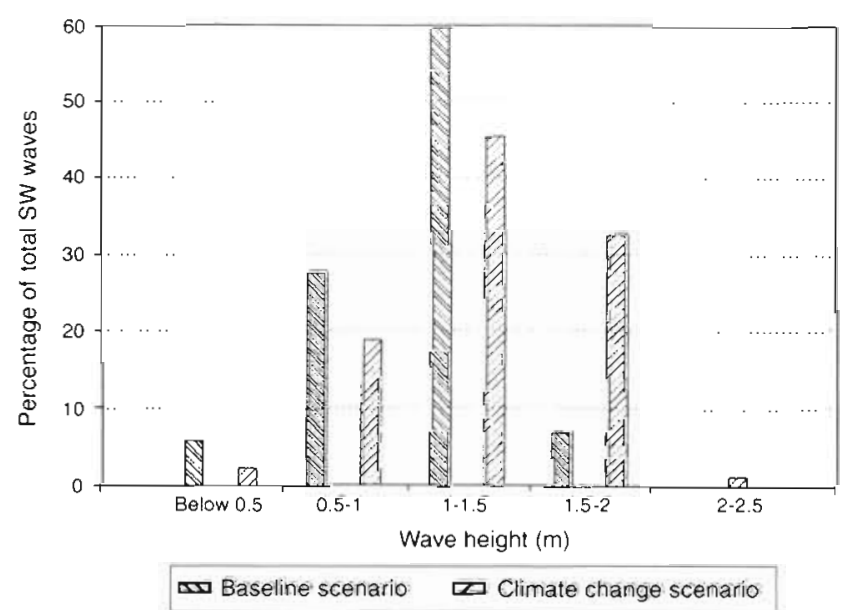

Fig. 6. Distribution of generated wave heights for the SW direction under baseline and climate change scenarios 
Table 1. Comparison of the propagation coefficients $(K)$ obtained for each scenario

\begin{tabular}{|c|c|c|c|c|c|c|}
\hline Wave direction & $\begin{array}{l}\text { Wave height } \\
\text { (m) }\end{array}$ & $\begin{array}{l}\text { Wave period } \\
\text { (s) }\end{array}$ & $\begin{array}{c}K \text { under baseline } \\
\text { scenario }\end{array}$ & $\begin{array}{l}K \text { under climate } \\
\text { change scenario }\end{array}$ & $\begin{array}{c}\% \text { increase } \\
\text { in } K\end{array}$ & $\begin{array}{c}\text { Change in } \\
\text { incidence angle }\end{array}$ \\
\hline E & 5 & 10 & 0.170 & 0.175 & 3.0 & $4^{\circ}$ \\
\hline ESE & 5 & 10 & 0.480 & 0.512 & 6.6 & $4^{\circ}$ \\
\hline $\mathrm{SE}$ & 6 & 12 & 0.985 & 0.871 & -11.5 & 0 \\
\hline SSE & 6 & 12 & 0.832 & 0.872 & 4.8 & 0 \\
\hline S & 4 & 10 & 1.190 & 1.140 & -4.4 & 0 \\
\hline SSW & 3 & 10 & 1.130 & 1.050 & -7.1 & $2^{\circ}$ \\
\hline SW & 2 & 8 & 1.110 & 1.120 & 1.1 & 0 \\
\hline WSW & 2 & 8 & 0.800 & 0.830 & 3.8 & 0 \\
\hline W & 2 & 8 & 0.420 & 0.440 & 6.8 & 0 \\
\hline
\end{tabular}

the incident wave height raised to the third power. A $15 \%$ difference in wave height would thus result in a $50 \%$ difference in the rock weight required. Due to the above-mentioned uncertainty in the behaviour of the propagation coefficients, a specific analysis would be necessary for each case in order to avoid errors derived from the application of general results.
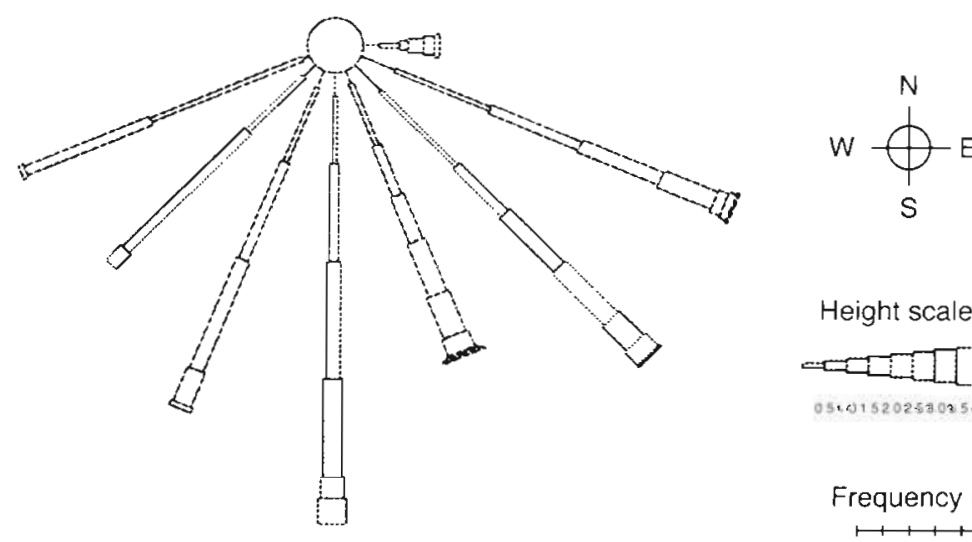

Height scale $(\mathrm{m})$

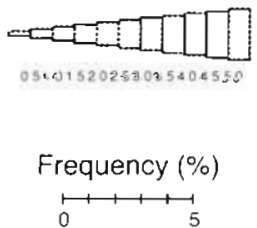

Fig. 7. Generated storm wave rose for the baseline scenario
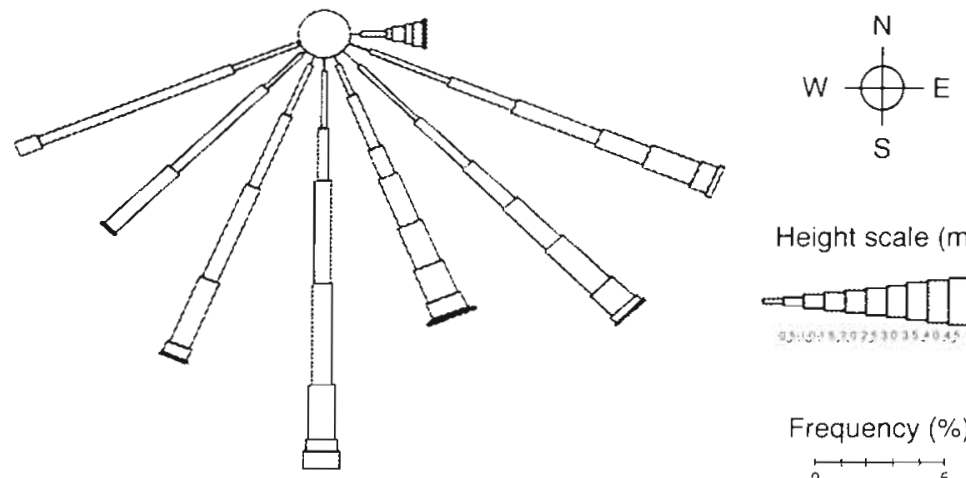

Height scale (m)

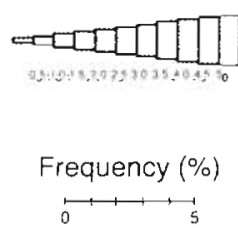

Fig. 8. Generated storm wave rose for the climate change scenario

\section{CONCLUSIONS}

As a general conclusion it is observed that, under the climate change scenario analyzed, the storm waves approaching the Montevideo coastline would increase in height, while their incidence angle would remain basically unchanged. It should be noted that the distribution of wind directions was not changed under the hypothetical scenario.

Generated storm wave roses and propagation coefficients for the most representative wave height and period for each incident wave direction were determined in this study only for 2 specific years. In spite of this, the results of the analysis performed provide insight into the sensitivity of the storm wave climate in Montevideo under a hypothetical climate change condition. A more precise evaluation should be carried out using all the wind information available and taking into account the propagation of all generated waves.

\section{LITERATURE CITED}

CERC (Coastal Engineering Research Center) (1984) Shore protection manual. Department of the Army, US Army Corps of Engineers, Washington, DC

Ebersole BA, Cialone MA, Prater MD (1986) RCPWAVE: a linear wave propagation model for engineering use. Coastal Engineering Research Center, Department of the Army, US Army Corps of Engineers, Washington, DC

Hurdle DP. Stieve RJH (1989) Revision of SPM 1984 wave hindcast model to avoid inconsistencies in engineering applications. Coast Engng 12:339-351 
IPCC (Intergovernmental Panel on Climate Change) (1994) Preparing to meet the coastal challenges of the 21 st century: Conference Report, World Coast Conference 1993. RIKZ, The Hague

Rijkswaterstaat (1991) Rising waters: impacts of the greenhouse effect for The Netherlands. Ministry of Transport and Public Works, Tidal Waters Division, The Hague

Teixeira L, Lorenzo E (1995) Application of a simple wave model to Montevideo's coast. In: Brebbia CA, Traversoni L, Wrobel LC (eds) Computer modelling of seas and coastal regions II. Computational Mechanics Publications, Southampton, p 185-193 